\title{
A family of rhomboid-like genes: Drosophila rhomboid-1 and roughoid/rhomboid-3 cooperate to activate EGF receptor signaling
}

\author{
Jonathan D. Wasserman, ${ }^{1}$ Sinisa Urban, and Matthew Freeman ${ }^{2}$ \\ MRC Laboratory of Molecular Biology, Cambridge CB2 2QH, UK
}

\begin{abstract}
As in mammals, the Drosophila EGF receptor controls many aspects of growth and development. The rate limiting component of Drosophila Egfr signaling is Rhomboid, a seven transmembrane domain protein, whose expression prefigures Egfr signaling. Little is known about the molecular mechanism of Rhomboid function but genetic evidence suggests that it controls the activation of the ligand Spitz, a TGF $\alpha$-like factor. Spitz/Egfr signaling regulates cell determination in the eye but here there is no apparent function for Rhomboid, an observation that casts doubt on this prevailing model of Rhomboid function. We describe our identification of six new rhomboid-like genes in Drosophila, and a large family of related genes present in organisms as diverse as bacteria and mammals; a human rhomboid homolog has also recently been described. Drosophila

rhomboid-3 corresponds to the roughoid mutation; it cooperates with rhomboid-1 to control Egfr signaling in the eye, thereby solving the puzzle of the apparent lack of Rhomboid-1 function there. Rhomboid-1 and Roughoid/Rhomboid-3 act in the signal-emitting not signal-receiving cell, supporting the idea that Spitz activation is regulated by Rhomboid-like molecules.
\end{abstract}

[Key Words: EGF receptor; Drosophila; Roughoid; Rhomboid; signaling; apoptosis]

Received October 25, 1999; revised version accepted May 9, 2000.

Rhomboid is a key trigger of EGF receptor activation in Drosophila and as such, controls many aspects of fly development. rhomboid expression is sufficient to activate Egfr signaling in all tissues, while loss of rhomboid mimics loss (or reduction) of Egfr signaling in almost all tissues (Bier et al. 1990; Freeman et al. 1992; RuoholaBaker et al. 1993; Sturtevant et al. 1993; Freeman 1994; Golembo et al. 1996; Gabay et al. 1997; zür Lage et al. 1997; Wasserman and Freeman 1998; Guichard et al. 1999). These results imply that in most places Rhomboid is essential in the Egfr pathway. Three activating ligands of the Drosophila Egfr have been described, the most developmentally significant being the TGF $\alpha$-like molecule, Spitz (Rutledge et al. 1992). Like the receptor itself, spitz transcription is temporally and spatially broad, posing the question of how the necessarily precise regulation of the signaling pathway is achieved. The answer lies in tightly controlled post-translational activation of Spitz. Like mammalian TGF $\alpha$, Spitz is synthesized as a functionally inert transmembrane protein; subsequently, the proteolytic release of the extracellular portion of the molecule gives rise to a soluble and potent

${ }^{1}$ Present address: Division of Neuroscience, Children's Hospital and Department of Neurobiology, Harvard Medical School, Boston, MA 02115 USA.

${ }^{2}$ Corresponding author.

E-MAIL mf1@MRC-LMB.CAM.AC.UK; FAX (44) 1223412142.
Egfr ligand (Freeman 1994; Schweitzer et al. 1995; Golembo et al. 1996). Unlike all other essential components of Egfr signaling, the expression of rhomboid is tightly restricted to sites of signaling activity - rhomboid expression prefigures Spitz signaling - and it has been proposed that Rhomboid attains its key role in the pathway by regulating the proteolytic cleavage of Spitz (Golembo et al. 1996; for reviews, see Wasserman and Freeman 1997; Bier 1998).

The prominence of Rhomboid in a pathway as critical to development and growth control as the Egfr/Ras/ MAP kinase cascade provides a strong incentive to understand its molecular mechanism. Rhomboid has seven transmembrane domains and an amino terminal hydrophilic region but beyond this few clues to its molecular function can be deduced from the protein sequence (Bier et al. 1990). By analogy to mammalian Egfr ligands that are similarly processed, we expect Spitz cleavage to be catalyzed by an ADAM-like protease (for recent review, see Black and White 1998), but Rhomboid resembles no known protease. Therefore, despite the genetic evidence implicating it in Spitz activation, the molecular details of how Rhomboid works remain elusive. Recently, human and rat homologs of rhomboid have been identified (Pascall and Brown 1998), suggesting that, like most other components of the pathway, its function may have been conserved. 
The Drosophila eye has served as a useful model for studying mechanisms of Egfr and Ras signaling. Here, at least five different roles for the receptor have been identified (Baker and Rubin 1989; Xu and Rubin 1993; Freeman 1996; Domínguez et al. 1998; Kumar et al. 1998; Spencer et al. 1998), the best characterized being its function in recruiting cells into the developing ommatidium - the individual unit of the fly compound eye (for review, see Freeman 1997). Each ommatidium contains eight photoreceptors, four cone cells that secrete lens material, and an average of eight pigment cells. These are recruited sequentially into the ommatidium by Egfr signaling: already determined cells signal to neighboring naive cells, thereby causing them to initiate differentiation. The newly recruited cells subsequently signal to other undetermined cells in a reiterative process (Freeman 1996). These cycles of Egfr signaling are mediated by Spitz which, in the eye as elsewhere, appears to act in a cleaved, soluble form. Despite the importance of Spitz and the Egfr in cell recruitment in the eye, we were surprised to find that there is no requirement for Rhomboid; unlike in other tissues, complete loss of Rhomboid causes no loss of recruitment (Freeman et al. 1992). This exception to the general requirement for Rhomboid in Egfr signaling casts significant doubt on the role of Rhomboid in Spitz activation; unless there is an additional protein that acts redundantly with Rhomboid.

In this paper we describe the identification of six new rhomboid-like genes in Drosophila; we have isolated full-length cDNAs from three of these and fully sequenced them, while three have emerged only in the last stages of preparing this paper from the annotated genome sequence of Drosophila. We show that the Rhomboids belong to a large family of related proteins throughout evolution. We have identified mutations in rhomboid-3 and find they correspond to one of the first described Drosophila mutations, roughoid. Rhomboid (we will refer to here as Rhomboid-1) and Roughoid/Rhomboid-3 act together to control cell recruitment (by triggering Egfr activation) in the developing eye. Genetic mosaics allow us to determine that the pair of proteins act only in the signal-emitting cell, not the cells that receive the signal via the Egfr. Our analysis also allows us to predict that there is a missing Egfr ligand that regulates cell death and survival in the developing eye and we have identified a candidate for this ligand.

\section{Results}

Identification of rhomboid-related genes in Drosophila

The eye is the only known Drosophila tissue where loss of Rhomboid does not mimic reduction or loss of Egfr signaling. This led us to speculate that there may be homologous genes that act redundantly with rhomboid. We subsequently identified three sequences from the Berkeley Drosophila Genome Project database that exhibited high similarity to rhomboid. We named these genes rhomboid-2, rhomboid-3, and rhomboid-4 (but see below for rhomboid-3). Both rhomboid-2 and rhom- boid-3 are cytologically located very close to the rhomboid-1 gene on the third chromosome, whereas we mapped rhomboid-4 to position 10C on the X chromosome by polytene chromosome in situ hybridization (Fig. 1A). Full length cDNAs were isolated for each of the new genes and their sequences were compared (Fig. 1C). The most highly conserved region spans the seven transmembrane domains; the hydrophilic amino terminus is strikingly divergent. This pattern of similarity is very like that between Drosophila rhomboid-1 and its recently identified mammalian homologs (Pascall and Brown 1998), and suggests that the transmembrane domains provide a core function of Rhomboid-like proteins. A phylogenetic tree derived from these sequences (Fig. 1B) indicates that rhomboid-3 is most closely related to rhomboid-1, followed by rhomboid-2; rhomboid-4 is the least related. The amino-terminal region of Rhomboid-4 contains two tandemly arranged EF-hand motifs that are putative calcium-binding domains (for review, see Ikura 1996). As we were completing this paper the annotated genome sequence of Drosophila was released. There are three further rhomboid-like genes predicted (rhomboid-5, rhomboid-6, and rhomboid-7) (see Fig. 1A). As we have not isolated full-length cDNAs for these, they are not included in the alignment shown in Figure 1C.

\section{A family of Rhomboid-like proteins is conserved throughout evolution}

We have used the fly and two mammalian rhomboidlike genes to search for related genes in sequence databases. The rhomboid genes are clearly a conserved family, with recognisable members throughout evolution. Similar genes have been sequenced not only in mammals but in plants, yeast, eubacteria, and archaebacteria (Table 1). The general pattern of similarity is like that described above-the most conserved region encompasses the transmembrane domains, while diverging in the hydrophilic amino termini. This striking conservation of rhomboid-like genes suggests that the primordial function of these proteins is a fundamental cellular process. The restriction of Drosophila Rhomboid-1 and Rhomboid-3 function to Egfr signaling (see below) presumably represents a specialization of this original function. None of the genes we have identified in the databases has a clearly assigned function.

\section{Mutations in rhomboid-3 affect eye development}

To understand the specific function of each of the Drosophila rhomboid genes, as well as the underlying core function of these proteins, we sought to identify mutations in them. Here we consider only rhomboid-3 that is located distal to rhomboid-1 on the third chromosome, in a region that includes the roughoid (ru) mutation, a recessive rough eye mutation that was one of the first Drosophila mutants to be identified (Strong 1920). In unrelated experiments (see below), we discovered a genetic interaction between roughoid and rhomboid-1 and this, coupled with the approximate genetic colocalization of 


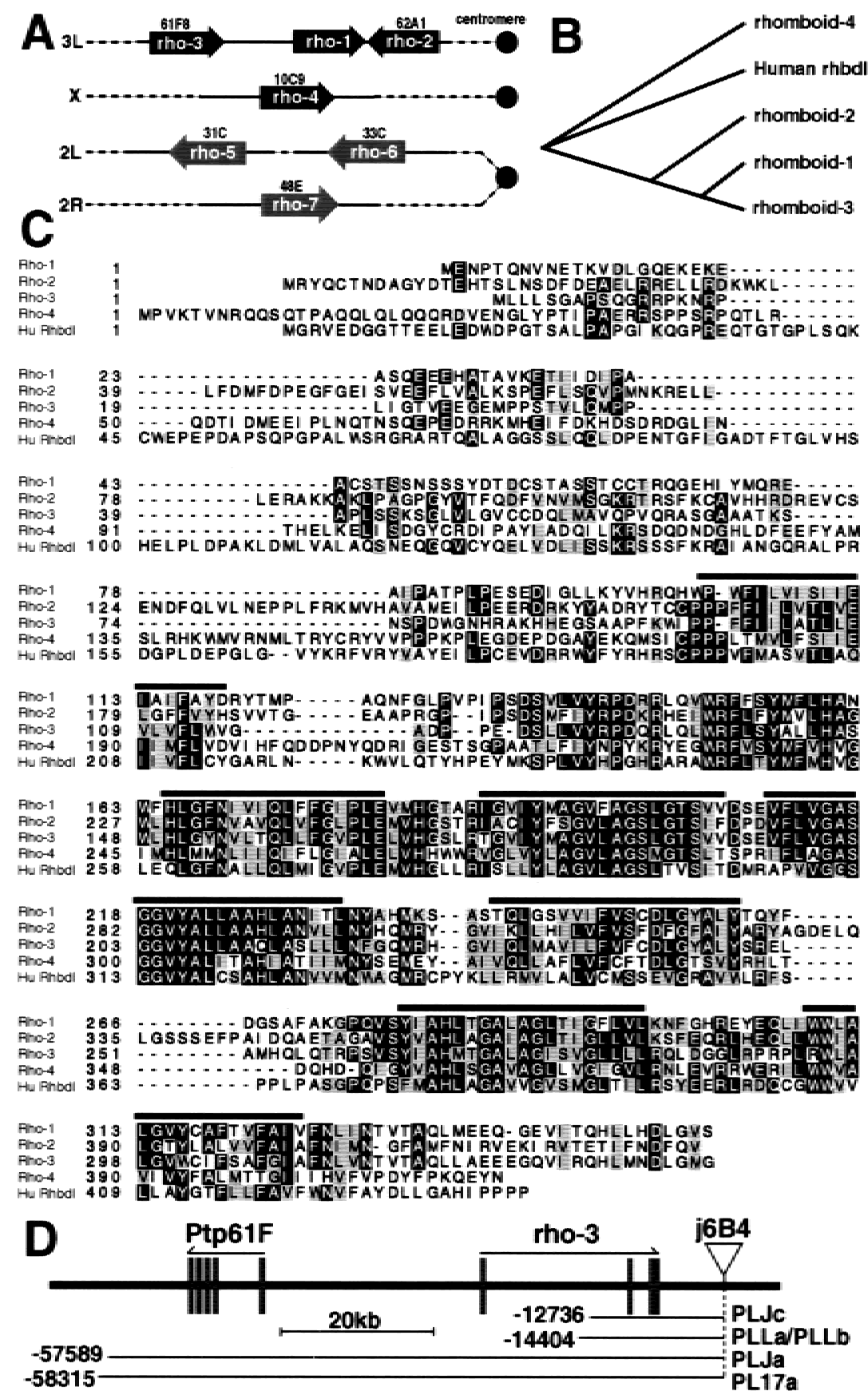

Figure 1. A family of rhomboid-like genes. (A) We have identified six new rhomboid-like genes in Drosophila and their positions are marked. (Black arrows) Genes we have isolated; (grey arrows) genes that are only identified by the genome project. Their current genome annotation numbers are as follows (rho2) CT5484; (rho-3) CT2274; (rho-4) CT4804; (rho-5) CT17046; (rho-6) CT34787; (rho-7) CT25796. (B) A phylogenetic tree derived from the ClustalW alignment of the Drosophila rhomboid-1 to rhomboid-4 and the human rhomboid-like gene, rhbdl. (C) A ClustalW-derived alignment of Drosophila Rhomboid-1 to Rhomboid-4 and Rhbdl. The predicted positions of the seven transmembrane domains are indicated by black lines. Rhomboid-4 has two consensus EF hand motifs located at residues 82-94 and 119-131. (Black shading) At least three of the sequences being identical; (grey shading) at least three of the sequences having similar residues. (D) The roughoid/rhom boid-3 locus. roughoid/rhomboid-3 spans four exons; the coding sequence is confined to exons $2-4$. The figure is shown with distal to the left. 1(3)j6B4 is the PlacW transposon that was the starting point of our screen for new roughoid alleles, and the extent of the mapped deletions is shown by horizontal lines. Note that $r u^{P L L a}$ and $r u^{P L L b}$ represent exactly the same deletion and may not have been independent events. All retain the 1(3)j6B4 transposon and the proximal flanking sequence is unaffected in every case. Numbered coordinates correspond to nucleotide position of breakpoints, on an arbitrary scale, where $1(3) j 6 B 4$ is at " 0 ". rhomboid-3 and roughoid led us to examine whether roughoid was in fact a mutation in rhomboid-3. The only allele of roughoid currently available, $r \mathrm{ru}^{1}$, is a spontaneous mutation first reported in 1920 (Strong 1920). We carried out a P-transposon-based mutagenesis to isolate new alleles, using as a starting stock a P-element that is inserted $\sim 6-\mathrm{kb}$ proximal to rhomboid-3. The screen allowed the isolation of either new $\mathrm{P}$ insertions, or of deletions flanking the P-element, as a result of Pinduced recombination (see Materials and Methods for details).

We identified 10 mutations that failed to complement the $r u^{1}$ allele and mapped in detail the mutational events that caused five of them. A molecular analysis of these mutations revealed that all the new roughoid alleles were deletions that remove DNA distal to the starting P-element and extend at least as far as the rhomboid-3 gene; they all remove the rhomboid-3 coding sequence (Fig. 1D). In all cases, the original P-element (1(3)j6B4) remains at the proximal end of the deletion and the proximal flanking sequence is unaffected. The new mutant stocks still only have a single P-element in them (detected by Southern blot; data not shown). Excision of this P-element failed to revert the rough eye phenotype, suggesting that the phenotype was generated by the genomic deletions, and not the P-element insertion itself. 
Table 1. Rhomboid-related proteins throughout evolution

\begin{tabular}{|c|c|c|}
\hline $\begin{array}{l}\text { GENBANK ENTREZ } \\
\text { Accession number }\end{array}$ & Species & P score \\
\hline P34356 & Caenorhabditis elegans & $3 e-80$ \\
\hline AAA91218 & Caenorhabditis elegans & $5 e-79$ \\
\hline 4506525 & Homo sapiens & $1 e-66$ \\
\hline AAA02747 & Saccharum hybrid & $6 e-62$ \\
\hline AAC33231 & Arabidopsis thaliana & $6 e-55$ \\
\hline АAB90231 & Archaeoglobus fulgidus & $2 \mathrm{e}-51$ \\
\hline CAA76716 & Rattus norvegicus & $3 e-49$ \\
\hline BAA30605 & Pyrococcus horikoshii & $4 \mathrm{e}-40$ \\
\hline CAB55154 & Caenorhabditis elegans & $2 \mathrm{e}-39$ \\
\hline AAD35669 & Thermotoga maritima & $8 \mathrm{e}-38$ \\
\hline P54493 & Bacillus subtilis & $2 \mathrm{e}-37$ \\
\hline CAA19250 & Streptomyces coelicolor & $4 e-37$ \\
\hline CAB55122 & Caenorhabditis elegans & $2 \mathrm{e}-36$ \\
\hline BAA19298 & Bacillus subtilis & $1 \mathrm{e}-35$ \\
\hline AAC65937 & Treponema pallidum & $3 e-30$ \\
\hline P44783 & Haemophilus influenzae & $2 \mathrm{e}-28$ \\
\hline CAA17304 & Mycobacterium tuberculosis & $3 e-26$ \\
\hline AAC28166 & Escherichia coli & $2 \mathrm{e}-20$ \\
\hline AAA58222 & Escherichia coli & $2 \mathrm{e}-20$ \\
\hline P53259 & Saccharomyces cerevisiae & $8 \mathrm{e}-19$ \\
\hline 014364 & Schizosaccharomyces pombe & $8 \mathrm{e}-15$ \\
\hline S61018 & Saccharomyces cerevisiae & $4 \mathrm{e}-10$ \\
\hline P53426 & Mycobacerium leprae & $5 e-06$ \\
\hline CAA21293 & Schizosaccharomyces pombe & $3 e-05$ \\
\hline
\end{tabular}

A representative list of genes clearly related to rhomboid, as predicted by Psi-Blast (after one iteration), searching the Genbank non-redundant database. Note that this is not a complete list. Most of the proteins are hypothetical, being derived from genome sequencing projects, and none has a defined function.

These are all hallmarks of deletions caused by P-element-induced male recombination (Preston and Engels 1996; Preston et al. 1996), which we presume was responsible for producing the nested set of distal deletions from the original P-element. The deletions that produced the new roughoid alleles fell into two classes: one viable with rough eyes, and the other lethal. Molecular mapping of the deletions shows that the viable alleles remove only rhomboid-3, whereas the lethal alleles extend to, and disrupt, the next most distal known gene, a genetically uncharacterized tyrosine phosphatase (Ptp61F; McLaughlin and Dixon 1993). All of the lethal alleles (i.e., those that remove rhomboid-3 and Ptp61F) are viable in trans to $\mathrm{ru}^{1}$ and have the characteristic rough eye.

We have focused our phenotypic analysis on two deletions $\left(r h o-3^{P L L b}\right.$ and $\left.r h o-3^{P L I C}\right)$ that break in the first intron of rhomboid-3 and thus remove the whole rhomboid-3 coding sequence but nothing more distally (Fig. 1D). We can infer from these two alleles that removal of rhomboid-3 alone causes a phenotype similar (although more extreme) to $r u^{1}$, and that loss of rhomboid-3 fails to complement $\mathrm{ru}^{1}$ (see below). On the basis of the analysis with the gene prediction programs Genewise and Genie, as well as the annotated Drosophila genome sequence, there is no predicted gene between the starting P-element and rhomboid-3. In summary, the new alleles of roughoid represented deletions of rhomboid-3; deletion of rhomboid-3 alone is sufficient to cause the roughoid phenotype; and no other mutagenic events were detected in the new roughoid alleles. Therefore, we conclude that roughoid is an allele of rhomboid-3. From now on, we will refer to the gene as roughoid/rhomboid-3, but for simplicity we will symbolise it as ru. The identity of roughoid and rhomboid-3 is confirmed by our observation that ectopic expression of a rhomboid-3 cDNA, under the hsp-70 promoter, suppresses the $\mathrm{ru}^{1}$ and rho$3^{P L L b}$ rough eye phenotype (data not shown).

roughoid/rhomboid-3 acts specifically in eye development

Flies with a complete deletion of roughoid/rhomboid-3 alone are viable, although the rough eye is more extreme than that of $r u^{1}$ (Fig. 2A-C) implying that $r u^{1}$ is an hypomorphic allele (a conclusion also supported by our observation that the eye phenotype of $r u^{1} / D f(r u)$ is more extreme than $\left.r u^{1} / r u^{1}\right)$. There is a variable loss of photoreceptors (typically one or two) in many ommatidia of the roughoid/rhomboid-3 adult eye (Fig. 2D-F). However, this disruption is not sufficient to account for the extent of roughness seen externally: the principle cellular phenotype can be seen in the developing pupal retina-the loss of cone and pigment cells (Fig. 2G-I). Examining the earliest stages of ommatidial development in larval imaginal discs from these mutants confirms this phenotype. Using a ubiquitous neural marker, Elav, we see few, if any, defects in the recruitment of photoreceptors (data not shown). Consistent with this, ommatidial initiation and the determination of the founding R8 photoreceptor, as determined by the expression of the atonal gene, is also normal in roughoid/ rhomboid-3 mutant discs (Fig. 2J). Therefore, the loss of photoreceptors seen in adult eyes appears to be caused by later loss of the cells rather than initial recruitment defects. However, cone cells are dramatically under-recruited, as evidenced by the substantial loss of staining by the cone cell marker Cut (Fig. 2K,L). The same phenotype is seen in $r u^{1}$ and $r u^{P L L b}$ discs, although the latter have a greater loss of cone cell precursors. Using TUNEL labeling we observed slightly elevated apoptotic cell death in the imaginal disc as compared to wild-type (data not shown); however, the amount was insufficient to account for the loss of cone cell staining observed. Furthermore, ubiquitous expression (under the control of the GMR enhancer) of the baculovirus $p 35$ gene in the eye, which prevents apoptotic cell death, did not significantly suppress the roughoid/rhomboid-3 phenotype. Therefore, we conclude that the cone cell deficiency resulted primarily from a failure of recruitment, rather than increased cell death.

roughoid/rhomboid-3 is expressed in the developing eye

The role of roughoid/rhomboid-3 in eye development is further supported by its expression pattern. Using RNA in situ hybridization, we find that expression is first detectable at the morphogenetic furrow, where ommatidial development begins (Fig. 2M). The transcript is 


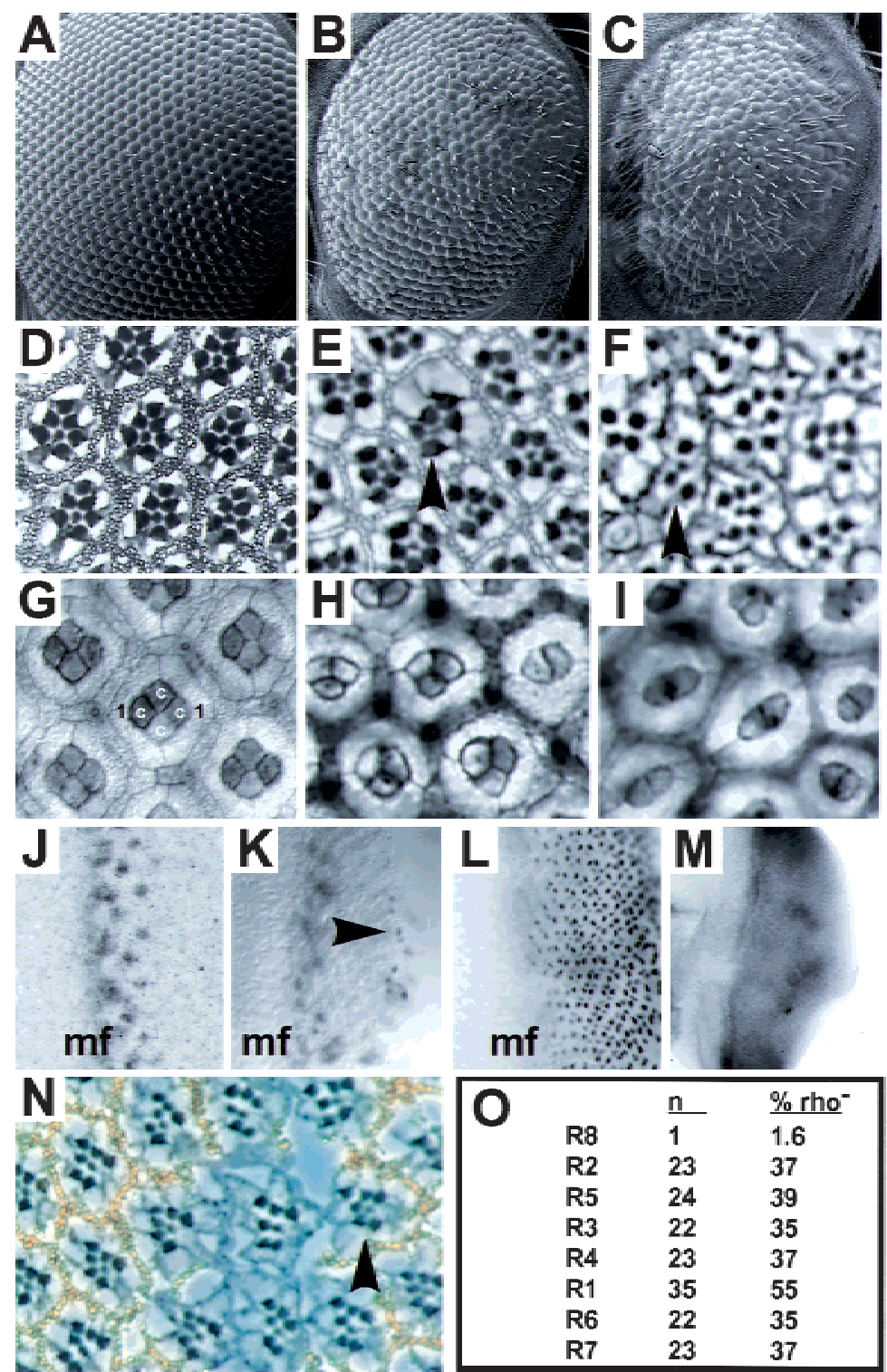

Figure 2. roughoid/rhomboid-3 phenotypes. $(A-C)$ Scanning electron micrographs of the external surface of $(A)$ wild-type, $(B) r u^{1} / r u^{1}$, and $(C) r u^{P L L b} / r u^{P L L b}$ eyes. Note that the regular array of facets is disrupted in rho-3 mutants; $r u^{1}$ is less severe than $r u^{P L L b}$, suggesting that $r u^{1}$ is an hypomorph. $(D-F)$ The $2 \mu \mathrm{m}$ sections through the adult eyes, $(D)$ wild-type, $(E) r u^{1} / r u^{1}$, and (F) $\mathrm{ru}^{P L L b} / \mathrm{ru}^{P L L b}$. There is some loss of photoreceptors in the rhomboid-3 mutants; again, $r u^{P L L b}$ is more severely affected than $r u^{1}$. Examples of ommatidia missing photoreceptors are indicated by arrowheads. $(G-I)$ Cobalt sulphide stained pupal retinas, $(G)$ wild-type, $(H)$ $r u^{1} / r u^{1}$, and $(I) r u^{P L L b} / r u^{P L L b}$. Wild-type ommatidia have four cone cells (c), surrounded by two primary pigment cells (1), embedded in a regular array of secondary and tertiary pigment cells. There are missing cone cells in most ommatidia mutant for alleles of rhomboid-3 and there are also missing pigment cells. $(J)$ A third instar imaginal disc from a $r u^{P L L b} / \mathrm{ru}^{P L L b}$ larva, stained with an antibody against Atonal. The normal expression of a stripe in the morphogenetic furrow $(\mathrm{mf})$, resolving into single cells— the R8 precursors-appears wild-type. $(K, L)$ Third instar imaginal discs stained with an antibody against Cut, which is expressed in cone cell precursors; $(K) \mathrm{ru}^{P L L b} / \mathrm{ru}^{P L L b}$ and $(L)$ wild-type. $r u^{P L L b} / r u^{P L L b}$ discs have a severe loss of cone cells; the out-of-focus staining just behind the morphogenetic furrow $(\mathrm{mf})$ is not due to cone cells but haemocytes that are attached to the basal side of the disc. A few cone cells can be seen (e.g., arrowhead) near the posterior of the disc. $(M)$ RNA in situ hybridization showing roughoid/rhomboid-3 expression posterior to the morphogenetic furrow in the eye imaginal disc. $(J-M)$ Posterior to the right. $(N, O)$ rhomboid-1, rhomboid-3 double mutant mosaic analysis. $(N)$ Ommatidia comprising a mosaic of wild-type and double mutant photoreceptors are found at the border of the scar left in the adult eye from a $r u^{1} r h o-1^{7 M 43}$ clone. The genotype of each photoreceptor can be determined by the presence or absence of pigment granules (the intense black specks adjacent to the blue/black rhabdomeres-the light gathering organelles; e.g., arrowhead). (O) Sixty-three mosaic ommatidia were scored. For the production of normal photoreceptors, only R8 showed a requirement for rhom boid-1, and roughoid/rhomboid-3; the percentage of mutant R1-R7 cells did not vary from controls. The one mutant R8 cell could indicate a low probability of forming a normal ommatidium when R8 in the absence of either Rhomboid; we think it more likely that it was mis-scored due to missing sections on the microscope slide (R8 pigment granules are often localized to only a small region of the cell and can therefore be missed if not all sections are collected).

present all the way to the posterior of the eye imaginal disc, implying that roughoid/rhomboid-3 is expressed throughout the period when photoreceptors and cone cells are recruited. The transcript appears to be restricted to the developing eye: no tissue-specific expression was observed in other imaginal discs or in the embryo by RNA in situ hybridization. Furthermore, we have not detected tissue-specific expression of rhomboid-2 or rhomboid-4 in either the embryo or imaginal discs.

\section{Rhomboid-1 and Roughoid/Rhomboid-3 cooperate to control photoreceptor cell recruitment in the eye}

In an attempt to define a role for rhomboid-1 in the developing eye, we have made mutant clones of several different rhomboid-1 alleles (Freeman et al. 1992; J.D. Wasserman and M. Freeman, unpubl.). Null mutations cause no defects in cell recruitment, leading us to conclude that Rhomboid-1 is not required in this process. Indeed, in clones generated using the Minute technique, entire rhomboid-1 $1^{-}$eyes were found to be phenotypically wild-type. In an apparently contradictory result, we did find that one EMS-induced allele, rho- $1^{7 M 43}$, caused a complete failure of cell recruitment-exactly the phenotype we had initially predicted for rhomboid-1. Although we do not know the molecular lesion in $r h o-1^{7 M 43}$, it behaves genetically like known rhomboid nulls in other tissues and has been extensively used in previous work (for example, Mayer and Nüsslein-Volhard 1988). One distinction between $r h o-1^{7 M 43}$ and the other alleles we 
examined was that it was induced on a multiply-marked chromosome, and we found that it still carries the $\mathrm{ru}^{1}$ mutation that is often present on such chromosomes. As described above, we have now discovered that roughoid is a mutation in rhomboid-3. Our description of rhomboid-1 roughoid/rhomboid-3 double mutants (see below) is therefore based on the phenotype of $\mathrm{ru}^{1} \mathrm{rho}$ $1^{7 M 43}$. Due to the very close proximity of the two genes, it is difficult to recombine $\mathrm{ru}^{1}$ with other rhomboid-1 alleles; instead we have induced new rhomboid-1 alleles on a $\mathrm{ru}^{1}$ chromosome and they confirm the interaction seen with rho-1 $1^{7 M 43}$ (not shown).

Clones of cells doubly mutant for rhomboid-1 and roughoid/rhomboid-3 do not survive into adult eyes, but rather leave a visible scar, at the edge of which there are genetically mosaic ommatidia that comprise a mixture of wild-type and mutant cells (Fig. 2N). By examining mosaic ommatidia that have formed normally, it can be concuded that only the R8 photoreceptor, the founding cell of each ommatidium, requires rhomboid-1 and roughoid/rhomboid-3 for normal photoreceptor recruitment to occur (Fig. 2O). We did find a single exampleout of 63 examined-of a normal ommatidium with an apparently mutant R8 but we suspect that this may have been an artefact (see legend to Fig. 2). As we have also found that neither gene alone is required for normal photoreceptor recruitment, this requirement for the pair of Rhomboids in $\mathrm{R} 8$ represents the only need for either gene in the formation of photoreceptors. However, note that this mosaic analysis technique cannot address which cells must express the pair of Rhomboids for normal cone cell development.

By examining imaginal discs, we can define more precisely the requirement in the R8 photoreceptor. Within rhomboid-1 roughoid/rhomboid-3 double mutant clones we see isolated cells that express the neuronal marker Elav (Fig. 3A). These clones look very similar to Egfr- clones and, as in the latter, we found that the isolated Elav-positive cells all express the R8-specific marker, Boss (Fig. 3C). Consistent with this, the transcription factor that specifies R8, Atonal, is expressed within rhomboid-1 roughoid/rhomboid-3 double mutant clones (Fig. 3E). In wild-type discs, Atonal first appears in all cells just ahead of the morphogenetic furrow and is gradually refined to evenly-spaced single cells that become the R8s (Jarman et al. 1995; Baker et al. 1996; Dokucu et al. 1996; see also Fig. 3F). In rhomboid-1 roughoid/rhomboid-3 clones there are excess Atonalpositive cells and these cells are disorganized (Fig. 3E), suggesting that the refinement and/or spacing mechanisms are disrupted. In addition to the absence of non-R8 photoreceptors, there are no Cut expressing cells in the body of the double mutant clones (Fig. 3G), indicating that cone cell determination does not occur. From these results we conclude that the only cells to initiate differentiation in the absence of Rhomboid-1 and Roughoid/ Rhomboid-3 are the R 8 cells: no subsequent recruitment occurs. Importantly, discs with clones mutant for rhomboid-1 alone are completely wild-type (Fig. 3B,D,F,H) but the rhomboid-1 roughoid/rhomboid-3 double mutant phenotypes closely resemble those caused by loss of the Egfr (Domínguez et al. 1998). This implies that in the eye the rhomboid-1 roughoid/rhomboid-3 pair combine to fulfill the role of Rhomboid-1 in other tissues as a positive regulator of Egfr signaling.

This implication was directly tested by examining MAP kinase activation in clones lacking both Rhomboids. In wild-type imaginal discs, the activated form of MAP kinase [as detected by an antibody specific for the diphosphorylated form of MAP kinase (Gabay et al. 1997)] is seen in regularly-spaced clusters of cells along the morphogenetic furrow. This MAP kinase activation is abolished upon removal of the Egfr (Kumar et al. 1998; J.D. Wasserman, S. Urban, and M. Freeman, unpubl.). Loss of rhomboid-1 and roughoid/rhomboid-3 together also removes it completely (Fig. 3I), whereas the loss of rhomboid-1 alone does not disrupt MAP kinase activation at all (Fig. 3J). This directly demonstrates that the loss of the combination of rhomboid-1 and roughoid/ rhomboid-3 disrupts Egfr activation of MAP kinase, and that the contribution of the $r u^{1}$ mutation to this loss is critical.

\section{Rhomboid-1 and Rhomboid-3 regulate the recruiting signal within the ommatidium}

To understand how Rhomboid-1 and Roughoid/Rhomboid-3 control Egfr signaling in the eye it is important to determine whether they act in the signal-emitting or signal-receiving cell. The Egfr itself is the principle receptor of recruiting signals in the ommatidium and, as such, is required in the cells being recruited. The observation that Rhomboid-1 and Roughoid/Rhomboid-3 are only required in the founding R8, but that in their absence R8 forms normally without subsequent recruitment of other cells, implies that the proteins are not needed for reception of the signal, but instead for its generation. This is directly confirmed by examining genetically mosaic ommatidia at the border of the clones in imaginal discs. In contrast to the absence of cell recruitment in the central part of clones, at the borders we find many examples of cells that are mutant for the two Rhomboids but are nevertheless recruited normally as non-R8 photoreceptors (Fig. 4A). This is direct proof that a cell can be recruited normally even if it has no Rhomboid-1 or Roughoid/Rhomboid-3, as long as it is adjacent to a wildtype cell. Similar non-autonomy is seen for cone cell recruitment (Fig. 4C): no cone cells are recruited in the center of a clone but mutant cells that are adjacent to wild-type cells can adopt a cone cell fate. This result is also confirmed when the loss of activated MAP kinase shown in Figure 3I is examined closely: MAP kinase activation can be seen in cells that are themselves mutant, when they are adjacent to wild-type cells. These results demonstrate that the rhomboid-1 roughoid/rhomboid-3 combination controls the generation of the recruiting signal, not its reception by recruited cells. As expected, spitz mutant clones also show the same non-autonomy (Fig. 4B,D) and the distance from wild-type tissue at which mutant cells can be recruited is a direct indication 
ru rho-1
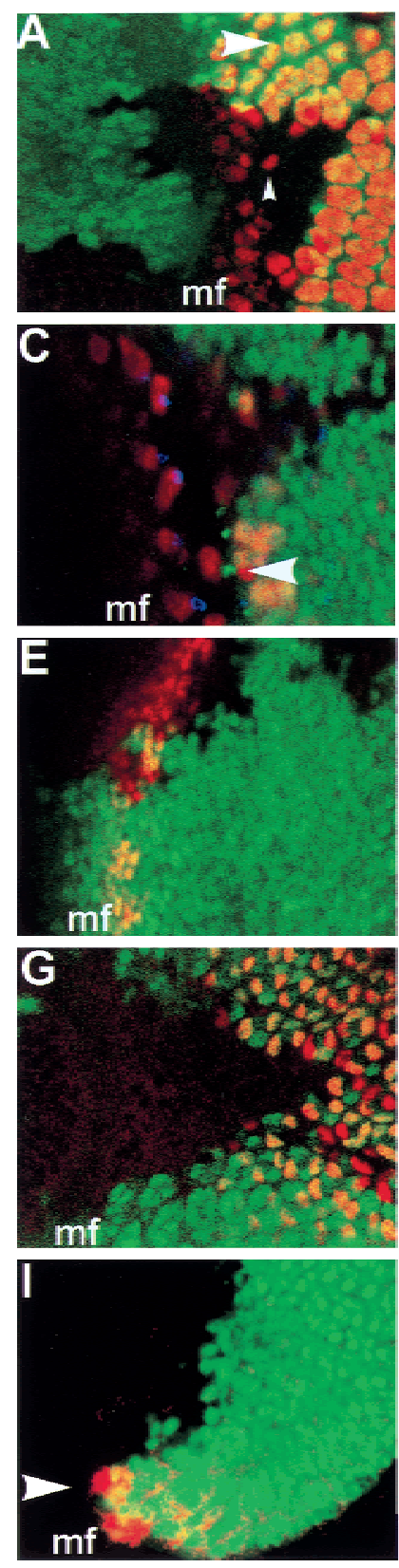

rho-1
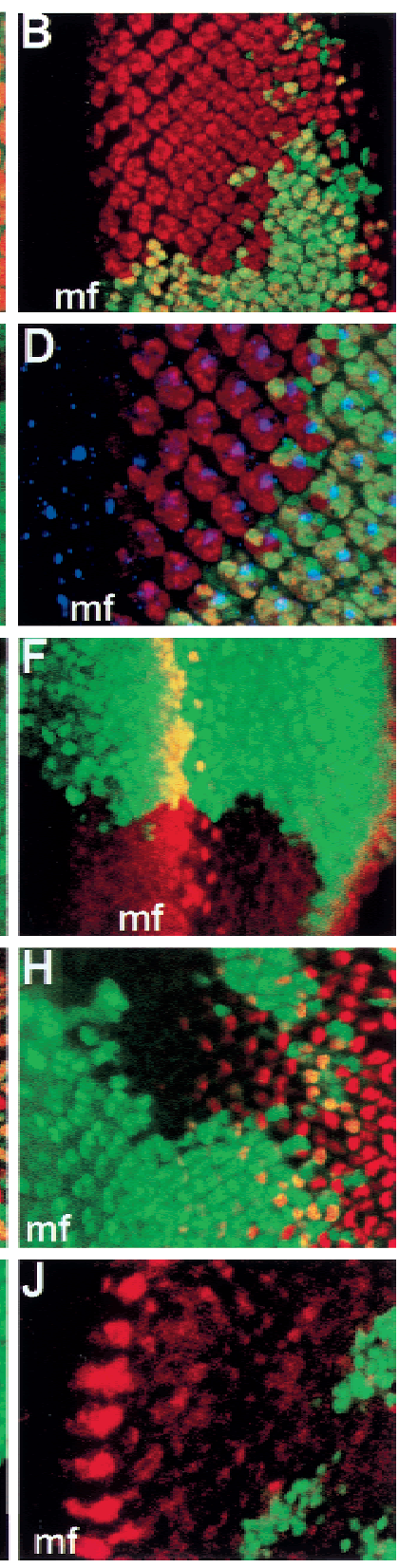

Figure 3. Eye disc phenotypes of single and double mutants. Mitotic clones in third instar larval imaginal eye discs are shown. In all cases the clone is negatively marked with nuclear GFP, shown in green; that is, the tissue that does not stain green is mutant. The overlap between green and red is yellow. $(A, C, E, G, I)$ Double mutant clones $\left(r u^{1}\right.$ rho- $\left.1^{7 M 43}\right)$ and $(B, D, F, H, J)$ rhomboid-1 null clones $\left(\right.$ rho- $\left.{ }^{P \Delta 5}\right)$. The morphogenetic furrow is labeled " $\mathrm{mf}^{\prime}$. (A) Elav expression (red) within $r u^{1} r h o-1^{7 M 43}$ double mutants: some neuronal cells differentiate close to the morphogenetic furrow (e.g., small arrowhead), but normal ommatidial clusters (e.g., large arrowhead) are missing. (B) rhomboid-1 null clones stained with Elav (red) show no disruption in ommatidial recruitment. $(C)$ The Elav-positive (red) cells within $r u^{1} r h o-1^{7 M 43}$ clones are also positive for the R8-specific antigen Boss (blue). Boss is expressed on apical membranes, while Elav is a nuclear antigen, accounting for the lack of colocalization of the red and blue signals. The bright green apical dots in part of the panel (e.g., arrowhead) are actually Boss staining: their green color is an artifact of the staining procedure. $(D)$ rhomboid-1 null mutant clones have normal Boss (blue) and Elav (red) expression. (E) The morphogenetic furrow $(\mathrm{mf})$ progresses through $r u^{1} r h o-1^{7 M 43}$ double mutant clones but is somewhat delayed; the furrow is labeled with anti-Atonal (red), which marks R8 precursor cells. In the double mutant clones there are excess Atonal-expressing cells in the furrow and, although they do resolve to single cells, there are more than in the adjacent wild-type tissue (compare with the evenly-spaced Atonal-positive cells in $F)$. (F) Atonal expression (red) is unaffected by rhomboid-1 null clones. $(G)$ There is no cone cell recruitment in the body of $r u^{1} r h o-1^{7 M 43}$ double mutant cells; cone cell precursors are labeled with anti-Cut (red). $(H)$ Cone cell recruitment (anti-Cut, red) is unaffected in rhomboid-1 null clones. (I) Clusters of cells with detectable activated MAP kinase are absent from $r u^{1} r h o-1^{7 M 43}$ clones; the arrowhead indicates a cluster expressing activated MAP kinase in the adjacent wild-type tissue. $(J)$ In contrast, MAP kinase activation occurs normally in the morphogenetic furrow of clones mutant for rhomboid-1 alone.

of the range at which Spitz can function: we estimate this to be no more than two or three cells, which agrees closely to our previous deduction (Freeman 1994, 1997). The range of non-autonomy in the rhomboid-1 roughoid/rhomboid-3 double mutant clones is indistinguishable (Fig. 4A,C), which is consistent with the idea that Rhomboid-1 and Roughoid/Rhomboid-3 control the activation of Spitz.

roughoid/rhomboid-3 mutations genetically interact with the Egfr signaling pathway

We are proposing that Roughoid/Rhomboid-3 is an important activator of the Egfr in eye development. A clear prediction of this proposal is that mutations in the gene will interact with mutations in known components of this pathway. Genetic interaction tests confirm this prediction. We find that null alleles of roughoid/rhomboid-3 interact dominantly with mutations in the Egfr itself $\left(E l p^{B 1}\right)$, spitz $\left(s p i^{s c p 1}\right.$ and $\left.s p i^{s c p 2}\right), \operatorname{Star}\left(S^{218}\right)$, and overexpressed argos (GMR-argos); the hypomorph $r u^{1}$ also interacts in some of these tests but less strongly than the null mutants. We also find that whereas rhomboid-1 mutations alone do not interact, the combination of loss of rhomboid-1 and roughoid/rhomboid-3 (ru ${ }^{1}$ rho- $1^{7 M 43}$ ) interacts most strongly of all. Therefore, these interactions correlate well with the phenotypic analysis described above. Our model places the Rhom- 

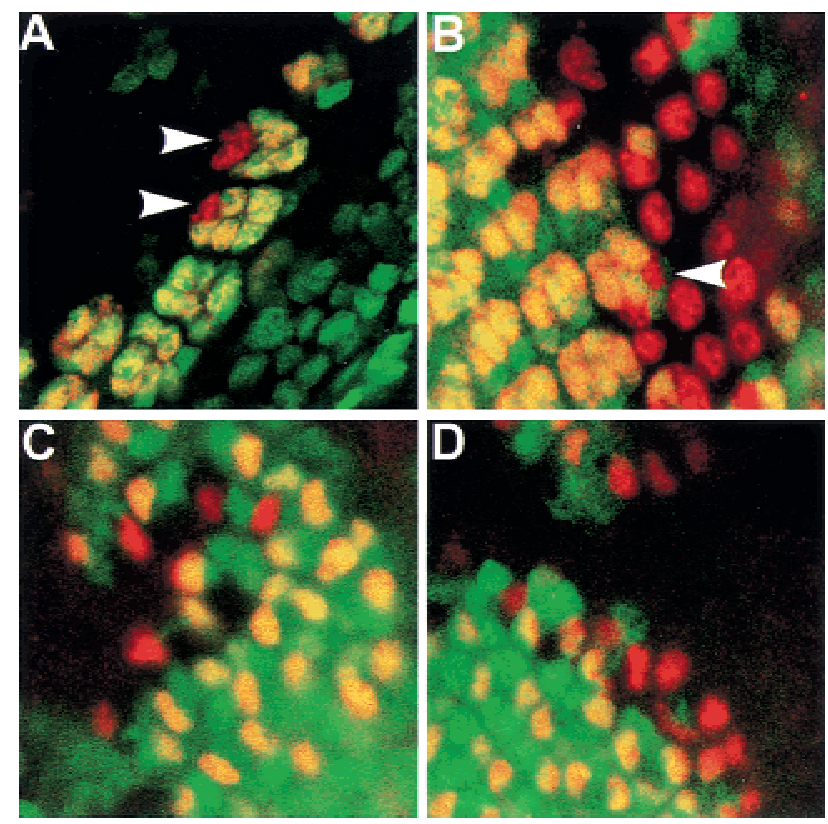

Figure 4. Non-autonomy in rhomboid-1 roughoid/rhomboid-3 and spitz mutant clones. $(A, C) r u^{1} r h o-1^{7 M 43}$ double mutant clones; $(B, D)$ spitz ${ }^{A 14}$ mutant clones. Immunostained third instar eye imaginal discs are shown stained with: $(A, B)$ anti-Elav $($ red); $(C, D)$ anti-Cut (red). In all cases the mutant cells are negatively marked with nuclear GFP (green), that is, wild-type cells stain green, mutant cells do not; the overlap of green and red is yellow. (A) At the border of $r u^{1} r h o-1^{7 M 43}$ double mutant clones, mutant cells can be recruited into wild-type ommatidia. The cells indicated with arrowheads (staining red only) are non-R8 photoreceptors that are mutant for rhomboid-1 and roughoid/ rhomboid-3. (B) Similarly, in spitz null clones, we can find nonR8 photoreceptors (eg arrowhead) at the border with wild-type tissue. Note that in spitz clones, the R8s that form in the absence of recruitment do not die; these are seen as isolated Elavexpressing cells within the clone. $(C) r u^{1} r h o-1^{7 M 43}$ double mutant cells can be recruited as cone cells (red) when adjacent to wild-type tissue. $(D)$ In spitz mutant clones, the same recruitment of cone cells occurs, again only in cells adjacent to wildtype tissue.

boids genetically upstream of the Egfr. Consistent with this, we find that overexpression of either rhomboid-1 or rhomboid-3 (both of which give strong phenotypes on their own-see below) is unable to rescue the phenotype caused by overexpression of a dominant negative form of the Egfr.

\section{Rhomboid-1 and Roughoid/Rhomboid-3 control cell survival in the eye disc}

It has been previously shown that the fly Egfr has a role in regulating cell survival in the developing eye (Domínguez et al. 1998). Intriguingly, the only known Egfr ligand to act in the eye, Spitz, does not control this survival signaling, as spitz ${ }^{-}$clones have little excess cell death (Fig. 5). This poses the question of whether the Egfr survival function is due to ligand-independent, constitu- tive signaling by the receptor or is triggered by another as yet unknown ligand. We find that rhomboid-1 roughoid/ rhomboid-3 clones have a substantial increase in cell death (Fig. 5A), like Egfr- clones but distinct from spitz clones. Moreover, they also have a characteristic tapered shape (a consequence of the apoptotic loss of cells toward the posterior of the clone), again like $E g f r^{-}$clones but not spitz ${ }^{-}$clones. Clones mutant for rhomboid-1 alone have no excess cell death. Therefore, loss of Rhomboid-1 and Roughoid/Rhomboid-3 permits cell death, but not by virtue of controlling Spitz activation (because loss of Spitz does not induce death). In conjunction with the non-autonomous behaviour of the Rhomboids, we take this as a strong suggestion that there is an unidentified Egfr ligand that controls cell survival in the eye.
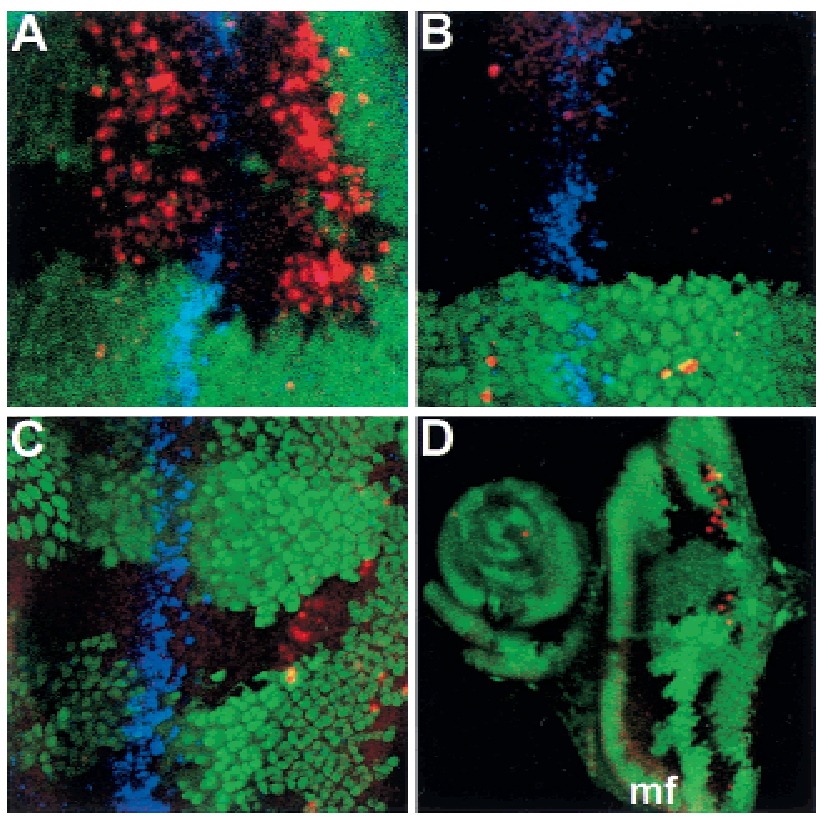

Figure 5. Cell death in rhomboid-1 roughoid/rhomboid-3 double mutant clones, rhomboid-1 clones, and spitz clones. Clones are negatively marked with nuclear GFP (green) and TUNEL stained for apoptosis in red; in $A$ to $C$ the morphogenetic furrow is indicated by Atonal expression (blue). (A) Many apoptotic nuclei (red) are seen in $\mathrm{ru}^{1} \mathrm{rho}-1^{7 M 43}$ double mutant clones. They occur in two main zones, one just ahead of the advancing morphogenetic furrow and one towards the posterior of the clone. $(B)$ In contrast, rhomboid-1 null clones (rho- $1^{P \Delta 5}$ ) show no excess of apoptosis over wild-type discs (data not shown). Note that there is some variability in the amount of apoptosis seen in wild-type discs: usually, very few nuclei can be found but sometimes there is a perceptible domain just ahead of the furrow; however, this never approaches the amount seen in $\mathrm{ru}^{1} \mathrm{rho}-1^{7 \mathrm{M} 43}$ double mutant clones (nor, for that matter, in Egfr mutant clones; Domínguez et al. 1998). (C,D) In spitz null clones $\left(s p i^{A 14}\right)$ there is little extra cell death, compared to wildtype discs. Typically we find a few apoptotic nuclei in the posterior regions of clones, which we take to be caused by the ultimate death of cells that have failed to be recruited in the absence of Spitz. Again, the amount of cell death is quite different from that seen in $r u^{1} r h o-1^{7 M 43}$ and Egfr mutant clones (compare with $A$ ). In $D$ the morphogenetic furrow is marked (mf). 
Ectopic expression of roughoid/rhomboid-3 mimics rhomboid-1

The ectopic expression of rhomboid-1 activates Egfr signaling in all tissues examined (for reviews, see Wasserman and Freeman 1997; Bier 1998). The effects of similarly expressing roughoid/rhomboid-3 were assessed to determine whether the redundancy between the two proteins in the eye reflects a common molecular mechanism. Overexpression of either gene in the developing eye causes severe disruptions (Fig. 6A,B). At the cellular level, excess cone and pigment cell recruitment is the primary phenotype (Fig. 6C,D), although we also see

UAS-rhomboid-1
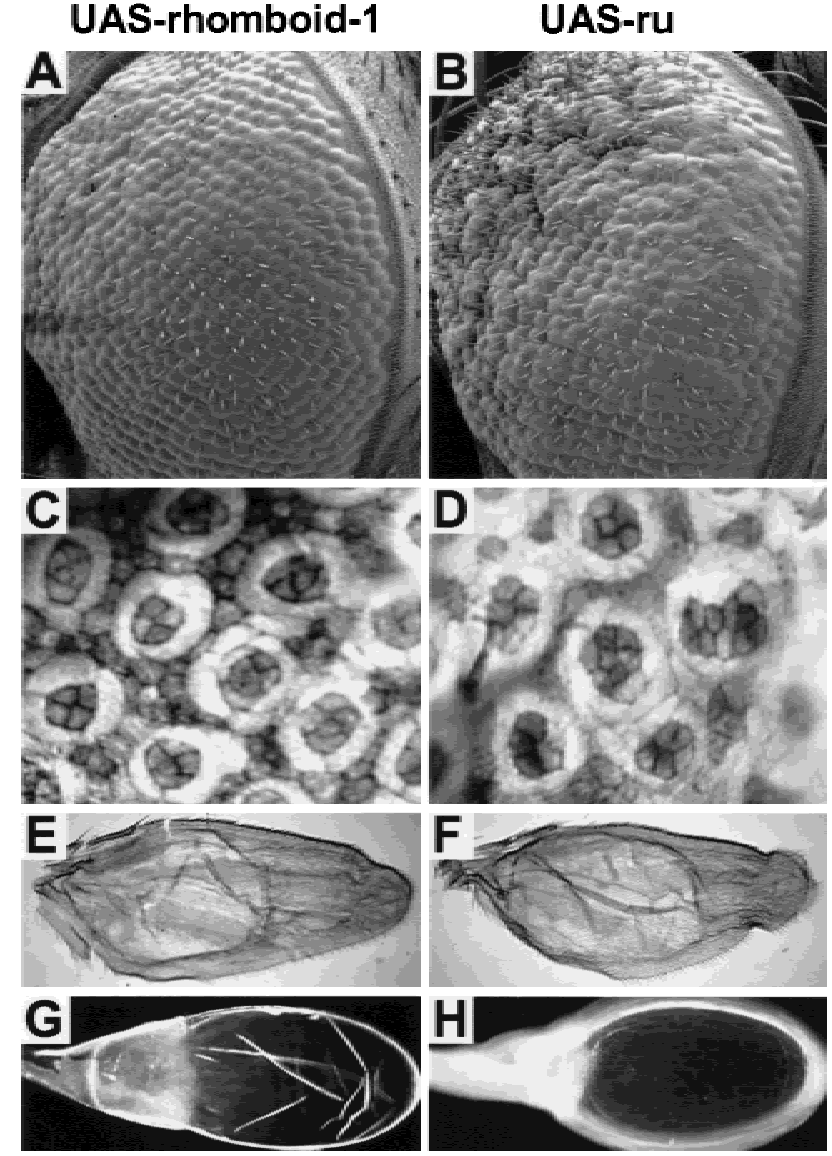

Figure 6. Ectopic expression of rhomboid-1 and roughoid/ rhomboid-3. Phenotypic effects of ectopic expression of: $(A, C, E, G)$ rhomboid-1; $(B, D, F, H)$ roughoid/rhomboid-3. $(A-D)$ Expression of either UAS-rhomboid-1 or UAS-ru under the control of GMR-Gal4, which is expressed in all cells behind the morphogenetic furrow, disrupts eye development. $(A, B)$ The external surface of the eye is roughened; $(C, D)$ cobalt sulphide stained pupal retinas have excess cone and pigment cells (compare with a wild-type retina in Figure $3 G$ ). Ectopic expression of roughoid/rhomboid-3 in the eye appears slightly stronger than rhomboid-1, but this could be an artifact due to insertion site of the respective transposons. $(E, F)$ UAS-rhomboid-1 and UAS-ru ectopically expressed by MS1096-Gal4, which is ubiquitous in the wing blade, leads to small, pigmented, blistered wings. $(G, H)$ UAS-rhomboid-1 and UAS-ru expressed under the control of CY2-Gal4, expressed in follicle cells, leads to a typical "dorsalized" egg phenotype. some excess photoreceptors (data not shown). A similar phenotype is also caused by ectopic expression of a constitutive form of the Egfr or of its ligand, Spitz (Freeman 1996). In the wing, the Egfr pathway promotes the formation of veins (Sturtevant et al. 1993), and ectopic expression of either rhomboid-1 or roughoid/rhomboid-3 again produces a similar phenotype: all cells in the wing are converted into vein cells, causing the wing to be small, excessively pigmented and blistered (Fig. 6E,F). Finally we examined the consequence of ectopic expression of roughoid/rhomboid-3 in the anterior follicle cells of the egg. These eggs have an expansion of dorsal tissue, including the respiratory appendages (Fig. 6G,H), yet again characteristic of Egfr hyperactivity and ectopic expression of rhomboid-1 (Ruohola-Baker et al. 1993). Therefore, in three different developmental contexts ectopic expression of roughoid/rhomboid-3 leads to a specific phenotype indistinguishable from that caused by rhomboid-1 and the ectopic activation of the Egfr pathway. Although rhomboid-3 function appears largely confined to the eye, these experiments all point to the conclusion that ectopic expression of Roughoid/Rhomboid-3 is sufficient to activate Egfr signaling in many tissues.

\section{Discussion}

We report here the existence of a large family of proteins with homology to the Drosophila rhomboid gene. We have identified six new rhomboid-like genes in flies and related genes in organisms as diverse as Arabidopsis, yeast, and bacteria-human rhomboid has also been recently reported (Pascall and Brown 1998). This very widespread conservation implies that the Rhomboid family proteins have a fundamental function within many cells. None of the Rhomboid-like proteins from species other than Drosophila have clearly assigned functions, so we are not able to use their conservation as a predictor of their underlying roles. However, there is compelling genetic evidence from Drosophila that Rhomboid-1 has a key role in intercellular signaling: it functions as an activator of the EGF receptor, probably by controlling the activation of the TGF $\alpha$-like ligand Spitz (Ruohola-Baker et al. 1993; Sturtevant et al. 1993; Freeman 1994; Golembo et al. 1996; zür Lage et al. 1997; Guichard et al. 1999). Indeed, Rhomboid-1 expression is the principal rate-limiting step in activation of the Ras/ MAP kinase pathway by the Egfr (Gabay et al. 1997). It should be emphasized that there is clear genetic evidence that, at least for Rhomboid-1 and Roughoid/ Rhomboid-3, their function is limited to Egfr signaling. Nevertheless, the existence of Rhomboid-like molecules in organisms without similar growth factor signaling implies that this function in Drosophila must represent a specialized form of a more generic function. Mutations in the other Drosophila rhomboids will provide a more comprehensive view of Rhomboid-like protein function in flies. The Egfr signaling pathway has been strikingly conserved between flies and vertebrates, and it will be important to discover whether Rhomboid-like proteins 
also have similar functions in other higher organisms, including mammals, whereas the Egfr pathway has substantial clinical importance (for review, see Casci and Freeman 1999).

\section{Rhomboid-3 solves a puzzle in eye development}

Until now, the observation that there is no requirement for rhomboid-1 in cell recruitment in the eye has been a significant gap in our understanding of Egfr signaling in development. The eye has been one of the key model systems for analyzing the Egfr pathway and has provided countervailing evidence to the model that Rhomboid is an essential element in Spitz processing. Our discovery that Roughoid/Rhomboid-3 is an eye-specific Rhomboid, and that the loss of both Rhomboid-1 and Roughoid/Rhomboid-3 mimics the phenotype of Egfr loss, now resolves this apparent inconsistency. An alternative explanation for the lack of a rhomboid-1 phenotype in the eye has been proposed by Spencer et al. (1998) who have reported that the neuregulin-like ligand, Vein, cooperates with Spitz to trigger the development of photoreceptors in the eye imaginal disc. However, the double mutant chromosome made by Spencer et al. (1998) also carried the $r u^{1}$ mutation (J.D. Wasserman, S. Urban, and M. Freeman, unpubl.) and therefore, was inadvertently mutant for roughoid/rhomboid-3 as well as rhomboid-1. In the absence of the $\mathrm{ru}^{1}$ mutation, we can see no evidence for an interaction between rhomboid-1 and vein, nor for Vein having a role in the cell recruitment stage of eye development (although there does appear to be a requirement for Vein in the earliest stages of furrow initiation at the posterior of the disc; J.D. Wasserman, S. Urban, and M. Freeman, unpubl.).

There has been much uncertainty about how Rhomboid-1 controls Egfr activation. Recently there has been growing evidence for the idea that it acts in the cell from which the signal emanates (perhaps by controlling Spitz processing). The principal evidence for this came from experiments in which ectopic expression of rhomboid in the embryonic midline caused lateral cells to alter their fates (Golembo et al. 1996). The simplest explanation for these results was that Rhomboid was controlling the production of a diffusible ligand, although it was not possible to rule out more indirect causes for this nonautonomy. More recently, Guichard et al. (1999) have shown that loss-of-function clones of rhomboid produce non-autonomous effects in the adult wing. Our results in the eye imaginal discs support these earlier conclusions and provide direct evidence that cells can be recruited as photoreceptors or cone cells in the absence of either Rhomboid-1 or Roughoid/Rhomboid-3-as long as they are adjacent to wild-type cells. Therefore, the evidence now overwhelmingly supports a model for Rhomboid function in which at least Rhomboid-1 and Roughoid/ Rhomboid-3 act in the signal-emitting cell, presumably by regulating the activation of Spitz. The molecular nature of this Spitz activation remains uncertain. It has been proposed that Rhomboid-1 regulates the proteolytic release of Spitz from the cell surface, but other mecha- nisms are also consistent with the current evidence. Very recently Bang and Kintner (2000) have examined the function of Rhomboid-1 in a Xenopus explant assay; they find that Rhomboid is essential for Egfr activation although in their assay Spitz release is not required, suggesting that Rhomboid may have a different function.

The discovery of Rhomboid-3 and its role in eye development allows us to refine our model of Egfr signaling in ommatidial cell recruitment. Each ommatidium is initiated by an R8 cell, which is determined by an Egfrindependent mechanism involving the expression of the bHLH transcription factor Atonal (Jarman et al. 1994, 1995; Baker et al. 1996; Dokucu et al. 1996). The newly founded R8s then start to express rhomboid-1 (Freeman et al. 1992) and roughoid/rhomboid-3 which between them cause Spitz in the R8 to be activated, thereby recruiting neighboring cells as photoreceptors. Later in development, all photoreceptors express rhomboid-1 and roughoid/rhomboid-3, and these then become the source of the Spitz that recruits cone cells; pigment cells are later recruited by a further iteration of the same process (Freeman 1997). It is notable that rhomboid-1 mutants alone have no phenotype, but loss of roughoid/ rhomboid-3 is sufficient to disrupt cone and pigment cell determination. This presumably reflects a more substantial role for Roughoid/Rhomboid-3 than Rhomboid1 , at least in the later stages of eye development. Nevertheless, only mutation of both can reproduce the complete absence of recruitment caused by loss of the Egfr, indicating that they act in cooperation at all stages of ommatidial recruitment.

Genetic evidence largely points to this straightforward model of cell recruitment. However, there is a subtle distinction, detected by mosaic analysis, between the requirement for Spitz and that for Rhomboid-1 and Roughoid/Rhomboid-3. Although the only photoreceptor to absolutely require Spitz is the R8-exactly as seen for rhomboid-1 roughoid/rhomboid-3 double mutantsthere is also a partial requirement for Spitz in the next two photoreceptors to be recruited, R2 and R5 (Freeman 1994; Tio et al. 1994). We see no such requirement for rhomboid-1 and roughoid/rhomboid-3. Although this may indicate that the rhomboid-1 roughoid/rhomboid-3 pair is not required in R2 and R5, it is also possible that this result is an artifact based on the absence of a chromosome completely null for rhomboid-1 and roughoid/ rhomboid-3.

\section{Rhomboids and cell death in the eye-evidence for a missing ligand}

We have found previously that the loss of the Egfr in clones in the developing eye induces ectopic cell death and that this cell death occurs at about the time that differentiation in the eye begins (Domínguez et al. 1998). Surprisingly, spitz ${ }^{-}$clones do not trigger this excess apoptosis. There are two possibilities to explain this discrepancy and we can now resolve them. Either the cell survival signaling by the Egfr is constitutive (that is ligand-independent) or it may be controlled by a ligand 
other than Spitz. Our observation that, like loss of the receptor, loss of Rhomboid-1 and Roughoid/Rhomboid-3 triggers cell death, implies that cell survival signaling in the eye must be mediated by another ligand, also controlled by Rhomboid-1 and Roughoid/Rhomboid-3. Gurken and Vein, the other known Egfr activating ligands in Drosophila, can be ruled out based on their phenotypes. Therefore, we propose that there is a novel ligand, activated by Rhomboid-1 and Roughoid/Rhomboid-3, which acts to protect cells from apoptosis in the eye. Interestingly, there is also evidence that there is a "missing" Rhomboid-controlled ligand in the wing (Guichard et al. 1999; Nagaraj et al. 1999). A candidate for this missing ligand has recently been sequenced by the Drosophila genome project; this gene has $49 \%$ identity with Spitz and all the hallmarks of a true Egfr ligand (J.R. Lee and M. Freeman, unpubl.). We speculate that this Spitz-like gene is the ligand that we predict to be missing in the eye and wing.

\section{What do Rhomboids do?}

The molecular mechanism of the Rhomboid-like protein family remains enigmatic. The only function we can deduce for Drosophila Rhomboid-1 and Roughoid/Rhomboid-3 is the activation of Spitz. But there is no experimental evidence, nor anything in the sequence of the proteins, to hint that they are proteases that catalyse the cleavage. Moreover, the enzymes that release similar ligands have been discovered in mammals and they are a recognizable family of ADAM metalloproteases (for recent review, see Black and White 1998); homologs exist in Drosophila, although we do not yet know which, if any, are responsible for Spitz cleavage.

There are some clues about the molecular functions of Rhomboids available from the conservation of different regions of the proteins. Notably, the transmembrane domains are the most highly similar, particularly domains 2,3 , and 4 . Within these domains there are some invariant charged residues that suggest the presence of a hydrophilic pocket that might constitute an enzymatic active site or a channel. It is striking that by comparison, the hydrophilic amino-terminal domains show little if any conservation, suggesting that they do not form part of the core function of the Rhomboid family. Indeed, Rhomboid-1 that has had its amino-terminal artificially removed retains its ability to activate Egfr signaling ( $M$. Sohrmann and M. Freeman, unpubl.). All Rhomboid-like proteins we have detected in the database do have a hydrophilic amino terminus, so we imagine that this may be an important regulatory region. In this regard, it is interesting that Rhomboid-4 of Drosophila, as well as human Rhomboid-like protein, have sequences that fit the consensus for $\mathrm{Ca}^{2+}$-binding $\mathrm{EF}$ hands.

\section{Materials and methods}

Isolation of rhomboid-2, rhomboid-3, and rhomboid-4 cDNA

Standard molecular biological techniques were performed according to Sambrook et al. (1989). rhomboid-2 was isolated from a 0-22 hr embryonic lambda gt11 library (gift of D. Huen, Cambridge) using a probe amplified from genomic DNA corresponding to the transmembrane domains. rhomboid-4 was recovered from an embryonic cDNA library in lambda ZapII (LD library, Berkeley Drosophila Genome Project), using a probe derived from a partial EST sequence (EST GH08858). Full-length rhomboid-3 cDNA was identified as an expressed sequence tag from the Berkeley Drosophila Genome Project (LP02893), recovered from a larval/pupal cDNA library.

\section{Transgenic Drosophila}

The complete cDNA sequence of rhomboid-3 was cloned as an EcoRI-XhoI fragment into pUAST (Brand and Perrimon 1993); flies were transformed by standard techniques. UAS-rhomboid-1 on the second chromosome was the gift of José-Felix de Celis and is also referred to as UAS-ve $e^{32}$ (de Celis et al. 1997). GMR-Gal4, CY2-Gal4, and MS1096-Gal4 have been described previously (Capdevila and Guerrero 1994; Freeman 1996; Queenan et al. 1997). GMR-p35 (Hay et al. 1994) was the gift of Bruce Hay.

\section{P-element mutagenesis}

To generate new alleles of roughoid, the PlacW insertion 1(3)J6B4 (which is located $\sim 6-\mathrm{kb}$ proximal of rhomboid-3) was placed in trans to a stable source of transposase $(\Delta 2-3)$ (Robertson et al. 1988). Approximately 50,000 male progeny were screened for rough eyes in trans to $\mathrm{ru}^{1}$. Viability and rough eye phenotypes were assayed by crossing new alleles to $D f(3 L)$ ru-22 and $D f(3 L)$ Ar14-8, both of which remove rhomboid-3 and rhomboid-1. All new alleles retained the orange eye colour from the PlacW transposon and thus did not represent excisions of the P-element; the deletions that we generated had the characteristics of P-transposon-mediated male recombination events, which frequently cause loss of DNA to one side of the P-element. Subsequent excision of the P-element was performed to confirm that the deletion, not the P-insertion, was the mutagenic event.

\section{Rescue of flanking genomic DNA}

To determine the molecular nature of the novel mutations, genomic DNA flanking the transposon was recovered by plasmid rescue and/or inverse PCR, using the protocol published on the Berkeley Drosophila Genome Project website. To ensure that each stock had only a single insertion of the PlacW transposon, genomic DNA was analysed by Southern blot using a 2-kb probe from the $3^{\prime}$ of the PlacW transposon. Deletion of the rhomboid-3 gene was also confirmed by Southern blotting.

\section{Generation of mitotic clones}

Clones in the eye of rho- $1^{P \Delta 5}$, rho- $1^{P \Delta 38}$ (Freeman et al. 1992), rho-1 $1^{\text {del1 }}$ (Bier et al. 1988), and rho-1 $1^{7 M 43}$ (Mayer and NüssleinVolhard 1988) were generated with the flp/FRT system by standard techniques (Xu and Rubin 1993). Disc clones were marked with nuclear GFP expressed under the control of the poly-ubiquitin promoter (Davis et al. 1995). Mitotic recombination was induced 24-48 hr after egg laying with a 60 min heat shock at $38^{\circ} \mathrm{C}$.

\section{Histology}

Immunofluorescent staining of imaginal discs and TUNEL staining were performed as described in Domínguez et al. 
(1998). Cobalt sulphide staining of 40-48 hr pupae was performed as described in Wolff et al. (1991). Adult clones were sectioned and examined as described by Freeman (1994). Flies were prepared for scanning electron microscopy as described by Kimmel et al. (1990). RNA in situ hybridizations were performed by standard techniques.

\section{Acknowledgments}

We gratefully acknowledge John Pascall (Babraham, UK) for his help identifying the fly rhomboid homolog in the databases; Tanita Casci for the data in Figure 3, I and J; Richard Smith for his excellent technical assistance; and Tanita Casci, Jeff Lee, and Marc Sohrmann for helpful discussions. Mariann Bienz and Tanita Casci gave us valuable feedback about the manuscript. J.D.W. was partly supported by a Trinity College Research Fellowship; S.U. was supported by a Trinity College External Studentship and by an NSERC (Canada) Scholarship.

The publication costs of this article were defrayed in part by payment of page charges. This article must therefore be hereby marked "advertisement" in accordance with 18 USC section 1734 solely to indicate this fact.

\section{References}

Baker, N.E. and Rubin, G.M. 1989. Effect on eye development of dominant mutations in Drosophila homologue of the EGF receptor. Nature 340: 150-153.

Baker, N.E., Yu, S., and Han, D. 1996. Evolution of proneural atonal expression during distinct regulatory phases in the developing Drosophila eye. Curr. Biol. 6: 1290-1301.

Bang, A.G. and Kintner, C. 2000. Rhomboid and Star facilitate presentation and processing of the Drosophila TGF-alpha homolog Spitz. Genes \& Dev. 14: 177-186.

Bier, E. 1998. Localized activation of RTK/MAPK pathways during Drosophila development. Bioessays 20: 189-194.

Bier, E., Ackerman, L., Barbel, S., Jan, L., and Jan, Y.N. 1988. Identification and characterization of a neuron-specific nuclear antigen in Drosophila. Science 240: 913-916.

Bier, E., Jan, L.Y., and Jan, Y.N. 1990. rhomboid, a gene required for dorsoventral axis establishment and peripheral nervous system development in Drosophila melanogaster. Genes \& Dev. 4: 190-203.

Black, R.A. and White, J.M. 1998. ADAMs: focus on the protease domain. Curr. Opin. Cell Biol. 10: 654-659.

Brand, A.H. and Perrimon, N. 1993. Targeted gene expression as a means of altering cell fates and generating dominant phenotypes. Development 118: 401-415.

Capdevila, J. and Guerrero, I. 1994. Targeted expression of the signaling molecule decapentaplegic induces pattern duplications and growth alterations in Drosophila wings. EMBO $\mathrm{I}$. 13: 4459-4468.

Casci, T. and Freeman, M. 1999. Control of EGF receptor signaling: Lessons from fruitflies. Cancer and Metastasis Rev. 18: $181-201$.

Davis, I., Girdham, C.H., and O'Farrell, P.H. 1995. A nuclear GFP that marks nuclei in living Drosophila embryos; maternal supply overcomes a delay in the appearance of zygotic fluorescence. Dev. Biol. 170: 726-729.

de Celis, J.F., Bray, S., and Garcia-Bellido, A. 1997. Notch signaling regulates veinlet expression and establishes boundaries between veins and interveins in the Drosophila wing. Development 124: 1919-1928.

Dokucu, M.E., Zipursky, S.L., and Cagan, R.L. 1996. Atonal,
Rough and the resolution of proneural clusters in the developing Drosophila retina. Development 122: 4139-4147.

Domínguez, M., Wasserman, J.D., and Freeman, M. 1998. Multiple functions of the EGF receptor in Drosophila eye development. Curr. Biol. 8: 1039-1048.

Freeman, M. 1994. The spitz gene is required for photoreceptor determination in the Drosophila eye where it interacts with the EGF receptor. Mech. Dev. 48: 25-33.

1996. Reiterative use of the EGF receptor triggers differentiation of all cell types in the Drosophila eye. Cell 87: 651660.

-1997. Cell determination strategies in the Drosophila eye. Development 124: 261-270.

Freeman, M., Kimmel, B.E., and Rubin, G.M. 1992. Identifying targets of the rough homeobox gene of Drosophila: Evidence that rhomboid functions in eye development. Development 116: 335-346.

Gabay, L., Seger, R., and Shilo, B.-Z. 1997. In situ activation pattern of Drosophila EGF receptor pathway during development. Science 277: 1103-1106.

Golembo, M., Raz, E., and Shilo, B.-Z. 1996. The Drosophila embryonic midline is the site of Spitz processing, and induces activation of the EGF receptor in the ventral ectoderm. Development 122: 3363-3370.

Guichard, A., Biehs, B., Sturtevant, M.A., Wickline, L., Chacko, J., Howard, K., and Bier, E. 1999. rhomboid and Star interact synergistically to promote EGFR/MAPK signaling during Drosophila wing vein development. Development 126: $2663-2676$.

Hay, B.A., Wolff, T., and Rubin, G.M. 1994. Expression of baculovirus P35 prevents cell death in Drosophila. Development 120: 2121-2129.

Ikura, M. 1996. Calcium binding and conformational response in EF-hand proteins. Trends Biochem. Sci. 21: 14-17.

Jarman, A.P., Grell, E.H., Ackerman, L., Jan, L.Y., and Jan, Y.N. 1994. atonal is the proneural gene for Drosophila photoreceptors. Nature 369: 398-400.

Jarman, A.P., Sun, Y., Jan, L.Y., and Jan, Y.N. 1995. Role of the proneural gene, atonal, in formation of Drosophila chordotonal organs and photoreceptors. Development 121: 20192030.

Kimmel, B.E., Heberlein, U., and Rubin, G.M. 1990. The homeo domain protein rough is expressed in a subset of cells in the developing Drosophila eye where it can specify photoreceptor cell subtype. Genes \& Dev. 4: 712-727.

Kumar, J.P., Tio, M., Hsiung, F., Akopyan, S., Gabay, L., Seger, R., Shilo, B.Z., and Moses, K. 1998. Dissecting the roles of the Drosophila EGF receptor in eye development and MAP kinase activation. Development 125: 3875-3885.

Mayer, U. and Nüsslein-Volhard, C. 1988. A group of genes required for pattern formation in the ventral ectoderm of the Drosophila embryo. Genes \& Dev. 2: 1496-1511.

McLaughlin, S. and Dixon, J.E. 1993. Alternative splicing gives rise to a nuclear protein tyrosine phosphatase in Drosophila. J. Biol. Chem. 268: 6839-6842.

Nagaraj, R., Pickup, A.T., Howes, R., Moses, K., Freeman, M., and Banerjee, U. 1999. Role of the EGF receptor pathway in growth and patterning of the Drosophila wing through the regulation of vestigial. Development 126: 975-985.

Pascall, J.C. and Brown, K.D. 1998. Characterization of a mammalian cDNA encoding a protein with high sequence similarity to the Drosophila regulatory protein Rhomboid. FEBS Lett. 429: 337-340.

Preston, C.R. and Engels, W.R. 1996. P-element-induced male recombination and gene conversion in Drosophila. Genetics 144: $1611-1622$. 
Preston, C.R., Sved, J.A., and Engels, W.R. 1996. Flanking duplications and deletions associated with P-induced male recombination in Drosophila. Genetics 144: 1623-1638.

Queenan, A.M., Ghabrial, A., and Schüpbach, T. 1997. Ectopic activation of torpedo/Egfr, a Drosophila receptor tyrosine kinase, dorsalizes both the eggshell and the embryo. Development 124: 3871-3880.

Robertson, H.M., Preston, C.R., Phillis, R.W., Johnson-Schlitz, D.M., Benz, W.K., and Engels, W.R. 1988. A stable genomic source of P element transposase in Drosophila melanogaster. Genetics 118: 461-470.

Ruohola-Baker, H., Grell, E., Chou, T.B., Baker, D., Jan, L.Y., and Jan, Y.N. 1993. Spatially localized rhomboid is required for establishment of the dorsal-ventral axis in Drosophila oogenesis. Cell 73: 953-965.

Rutledge, B.J., Zhang, K., Bier, E., Jan, Y.N., and Perrimon, N. 1992. The Drosophila spitz gene encodes a putative EGF-like growth factor involved in dorsal-ventral axis formation and neurogenesis. Genes \& Dev. 6: 1503-1517.

Sambrook, J., Fritsch, E.F., and Maniatis, T. 1989. Molecular cloning: A laboratory manual, 2nd Ed. Cold Spring Harbor Laboratory Press, Cold Spring Harbor, NY.

Schweitzer, R., Shaharabany, M., Seger, R., and Shilo, B.-Z. 1995. Secreted Spitz triggers the DER signaling pathway and is a limiting component in embryonic ventral ectoderm determination. Genes \& Dev. 9: 1518-1529.

Spencer, S.A., Powell, P.A., Miller, D.T., and Cagan, R.L. 1998. Regulation of EGF receptor signaling establishes pattern across the developing Drosophila retina. Development 125: 4777-4790.

Strong, L.C. 1920. roughoid, a mutant located to the left of sepia in the third chromosome of Drosophila melanogaster. Biol. Bull. Woods Hole 38: 33-37.

Sturtevant, M.A., Roark, M., and Bier, E. 1993. The Drosophila rhomboid gene mediates the localized formation of wing veins and interacts genetically with components of the EGF-R signaling pathway. Genes \& Dev. 7: 961-973.

Tio, M., Ma, C., and Moses, K. 1994. Spitz, a Drosophila homo$\log$ of transforming growth factor-alpha, is required in the founding photoreceptor cells of the compound eye facets. Mech. Dev. 48: 13-23.

Wasserman, J.D. and Freeman, M. 1997. Control of EGF receptor activation in Drosophila. Trends Cell Biol. 7: 431-436.

. 1998. An autoregulatory cascade of EGF receptor signaling patterns the Drosophila egg. Cell 95: 355-364.

Wolff, T. and Ready, D.F. 1991. Cell death in normal and rough eye mutants of Drosophila. Development 113: 825-839.

$\mathrm{Xu}, \mathrm{T}$. and Rubin, G.M. 1993. Analysis of genetic mosaics in developing and adult Drosophila tissues. Development 117: 1223-1237.

zür Lage, P., Jan, Y.N., and Jarman, A.P. 1997. Requirement for EGF receptor signaling in neural recruitment during formation of Drosophila chordotonal sense organ clusters. Curr. Biol. 7: 166-175. 


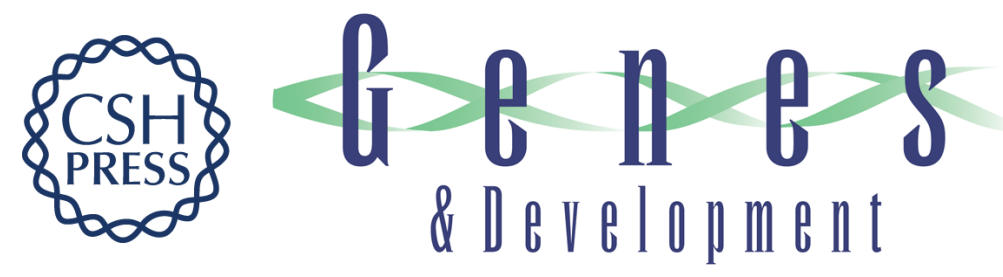

\section{A family of rhomboid-like genes: Drosophila rhomboid-1 and roughoid/rhomboid-3 cooperate to activate EGF receptor signaling}

Jonathan D. Wasserman, Sinisa Urban and Matthew Freeman

Genes Dev. 2000, 14:

Access the most recent version at doi:10.1101/gad.14.13.1651

References This article cites 46 articles, 28 of which can be accessed free at:

http://genesdev.cshlp.org/content/14/13/1651.full.html\#ref-list-1

License

Email Alerting

Receive free email alerts when new articles cite this article - sign up in the box at the top

Service right corner of the article or click here.

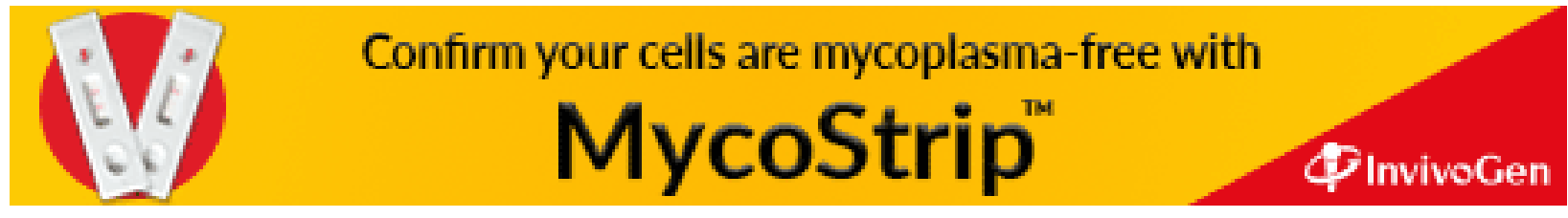

